\title{
DIFFERENT APPROACHES TO SURGICAL TREATMENT OF MULTIPLE CHONDROMATOSIS OF THE SHOULDER JOINT
}

Rybinin M.V., Gvozdev M.A., Avdeev A.I., Saprykin A.S.

Vreden Russian Research Institute of Traumatology and Orthopaedics, St. Petersburg, e-mail:

ryabininm@rambler.ru

Aims.

The aim of this article is to present the features of the clinical picture, pathophysiology, diagnosis and long-term treatment outcomes of multiple synovial chondromatosis, by the example of two patients, using total reverse endoprosthesis replacement and arthroscopic techniques.

Materials and methods.

This article describes the features of the clinical picture and intraoperative picture of synovial chondromatosis of the shoulder joint and long-term treatment outcomes. A clinical example of diagnosis and treatment of this disease in two patients is presented.

Results.

In the first case with early ambulation, diagnosis and satisfactory condition of the shoulder joint, arthroscopic intervention with removal of intra-articular bodies and local synovectomy was carried out. Histological examination confirmed the diagnosis of primary synovial chondromatosis in the first case. In the second case with late ambulation, post-traumatic arthritic changes in the shoulder joint, it was decided to hold an open interference with replacement arthroplasty. Histological examination confirmed the diagnosis of secondary synovial chondromatosis in the second case.

Conclusions.

In the early and late postoperative period, both patients noted a good functional outcome.

Keywords: synovial chondromatosis, shoulder joint, reserve endoprosthesis replacement, intra-
articular cartilagenous body, arthroscopy.

\section{INTRODUCTION.}

Synovial chondromatosis (SC) is a rare benign lesion of the synovium; morbidity peaks in the fifth decade of life. The most common symptoms are pain (85\% to $100 \%$ ), swelling (42\% to $58 \%$ ), and lesser joint movement amplitude (38\% to 55\%). As a rule, this pathology affects one large joint, most often the knee (46\%), sometimes the hip, the ulnar joint, the wrist, and the ankle. According to the literature, the shoulder is only affected in about 5\% of all cases. Russian and international research data prove men to be twice more likely to develop this pathology than women [1-3].

As of today, two forms of SC are identified: primary synovial chondromatosis (PSC) and secondary synovial chondromatosis (SSC). PSC occurs spontaneously and manifests as focal cartilaginous metaplasia in the synovium; the foci are ultimately loosened and form loose intraarticular bodies.

Currently, most SC patients receive arthroscopy for treatment; however, late diagnosis leads to a severely damaged joint with multiple intraarticular bodies, leaving open radical intervention as the only solution [5-7].

The goal hereof is to describe the clinical picture, pathophysiology, diagnosis, and remote outcome of treating multiple synovial chondromatosis; evidence is taken from the histories of two patients; treatment methods in use are reverse total replacement and arthroscopy.

\section{MATERIALS AND METHODS. Patient 1}

Woman, 27 years old, complaints about pain and limited right shoulder movement; both 
symptoms occur due to physical exertion. No injury according to her. Had had pain since 18 . No treatment received thus far. Since the age of 25 , the pain grew stronger, joint movement became restrained. Was treated at the Vreden Russian Research Institute of Traumatology and Orthopaedics in October 2016. The objective examination did not reveal any abnormalities in the right shoulder outline. Palpation caused painful sensation around the right shoulder. Movements restrained with crepitus: $55^{\circ}$ abduction, $45^{\circ}$ flexion, $40^{\circ}, 60^{\circ}$ medial rotation, $60^{\circ}$ lateral rotation. Right shoulder MRI dd. July 28, 2016: tenosynovitis of the long biceps head sheath; chondromatosis.

\section{Patient 2}

Man, 55 years old, complaints of pain, restrained active movement in the right shoulder. First injured in 1983: the head of the right humerus dislocated when a heavy-lift bar was behind the head. The patient had since then had some 50 dislocations, fixed them himself. Sought medical help at the hospital of residence, as well as the Kiev Research Institute of Traumatology and Orthopedics, in 2009-2010; diagnosed with deforming arthrosis, right-shoulder chondromatosis. No surgery. Was treated at the Vreden Russian Research Institute of Traumatology and Orthopaedics in March 2016. Examination identified moderate hypotrophy of the deltoid muscle, as well as of the dextral rotators. Palpation caused a painful sensation around the right shoulder. Movements restrained considerably, crepitus: $25^{\circ}$ abduction, $30^{\circ}$ flexion, $20^{\circ}$ extension, zero rotation. Rightshoulder X-ray dated March 3, 2016 showed III-degree deforming arthrosis with multiple loose bodies in the articular cavity, see Figure 1.

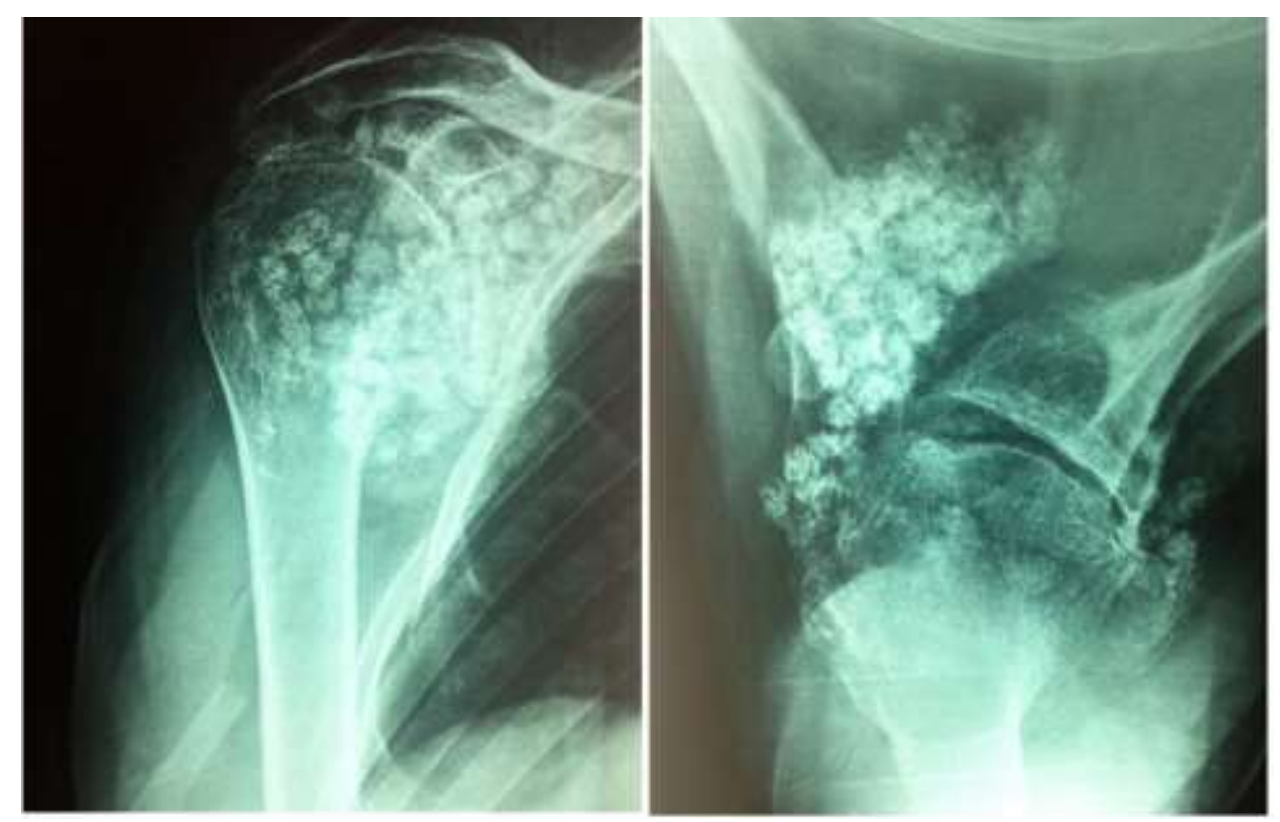

Figure 1. X-rays of the patient upon hospitalization: right shoulder in the frontal and axial views, Patient 2

This research was approved by the Ethics Committee of the Vreden Russian Research Institute of Traumatology and Orthopaedics, Ministry of Health of Russia. The goals and methods were clarified to the patients, who gave their informed consent in writing to be examined and treated for further publication of the collected data. 
RESULTS. Given the young age, no damage to the shoulder, and small loose intraarticular bodies as shown in the MRI in Patient 1, it was decided to perform diagnostic arthroscopy of the right shoulder to remove the loose intraarticular bodies. In a beach chair position, joint examination revealed that the Riedel sheath was full of chondromatosis bodies, the synovium was inflamed and hypertrophied. Local synovectomy was performed, multiple loose intraarticular bodies removed, see Figure 2.

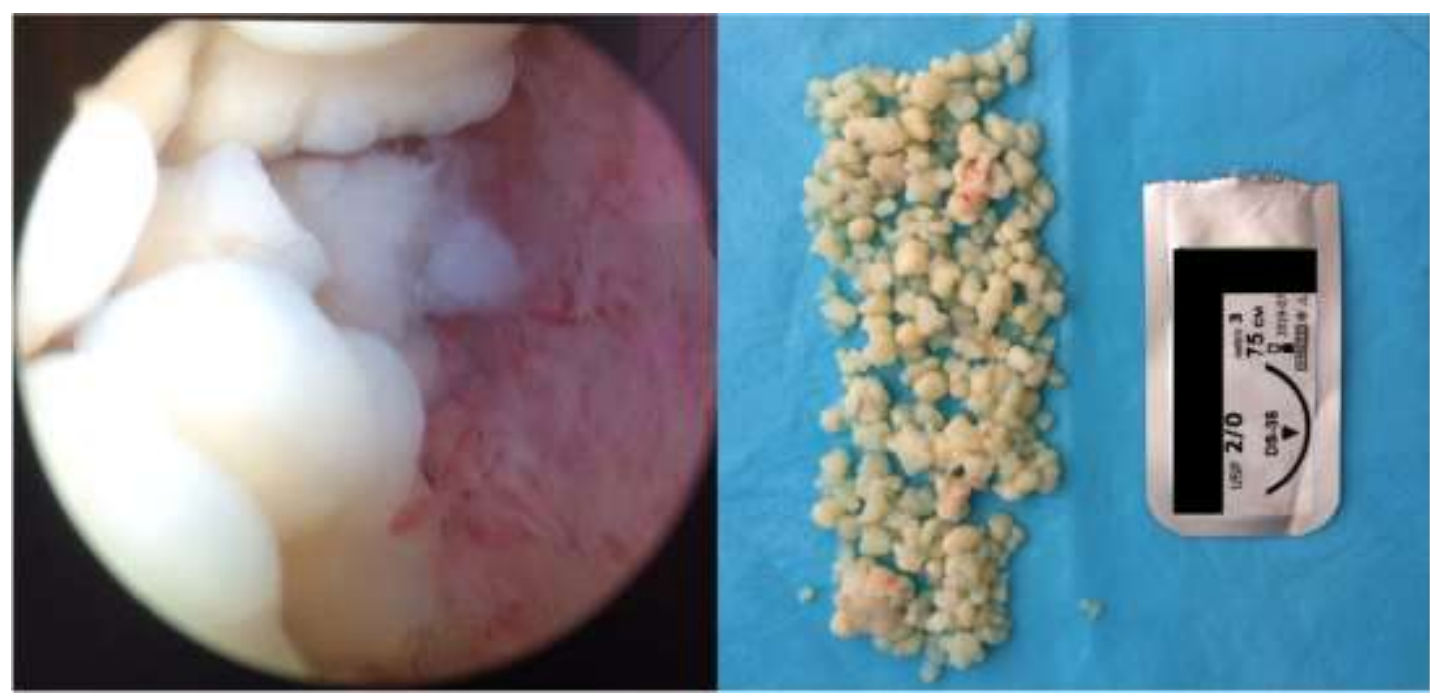

Figure 2. Overview of chondromatosis bodies in the articular cavity; removed bodies, Patient 1

The postoperative histological test of the bodies confirmed primary synovial chondromatosis. Eighteen months after surgery, the patient had no complaints, the right shoulder was fully functional, and the woman was able to perform her daily, professional, and sporting activities as usual, see Figure 3.

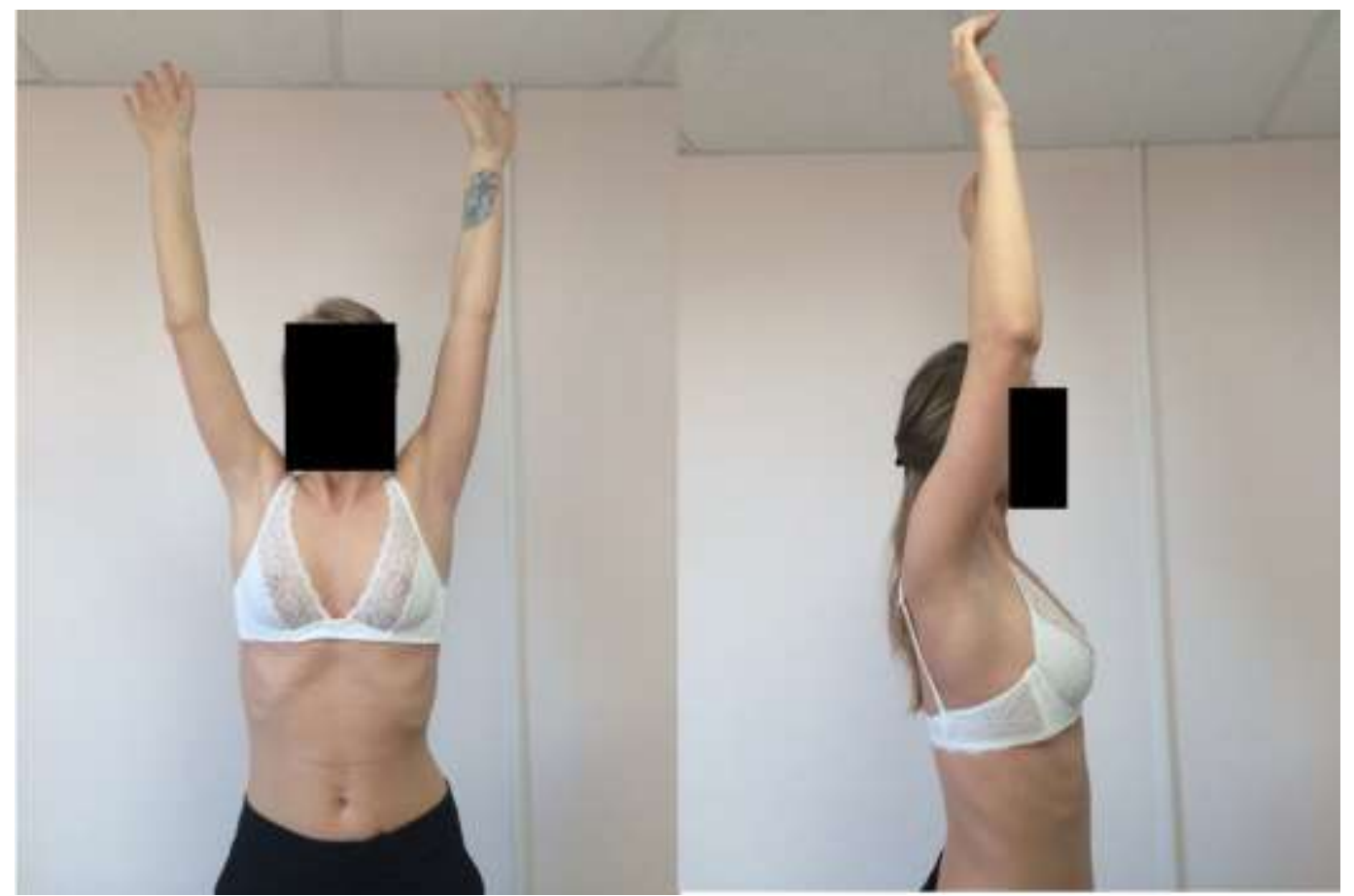

Figure 3. Photos of the patient 18 months after the operation (first case) 
dysfunction in Patient 2, a decision was made to perform reverse total replacement of the right shoulder. Shoulder arthrotomy was performed via a delta pectoral approach. Multiple (100+) intraarticular bodies were identified in all joint compartments, removed (Figure 4).

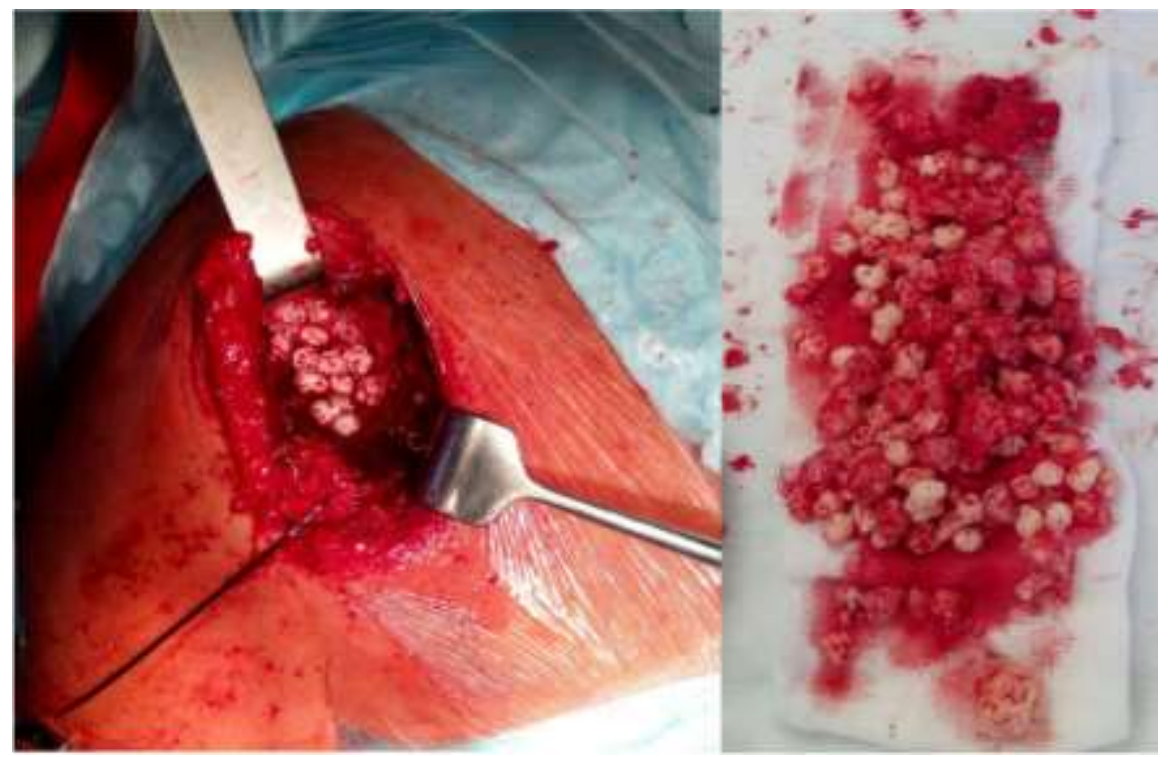

Figure 4. Overview of chondromatosis bodies in the articular cavity; removed bodies, Patient 2

A DePuy Delta Extend reverse shoulder implant was implanted in the patient, see Figure 5.

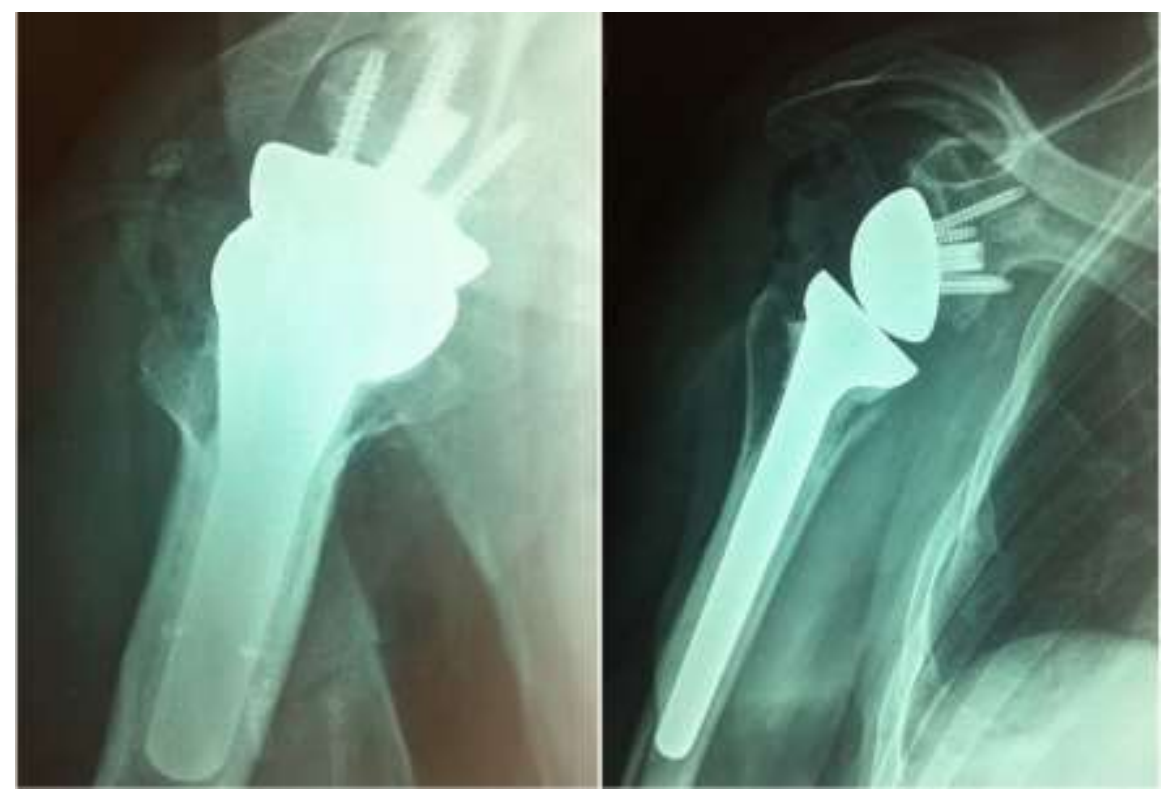

Figure 5. Patient's post-surgery X-ray, frontal and axial view, Patient 2

Postoperative histological analysis of the removed bodies confirmed secondary synovial chondromatosis. Two years after surgery, the patient had no complaints and was fully able to perform daily household and professional tasks, see Figure 6. 


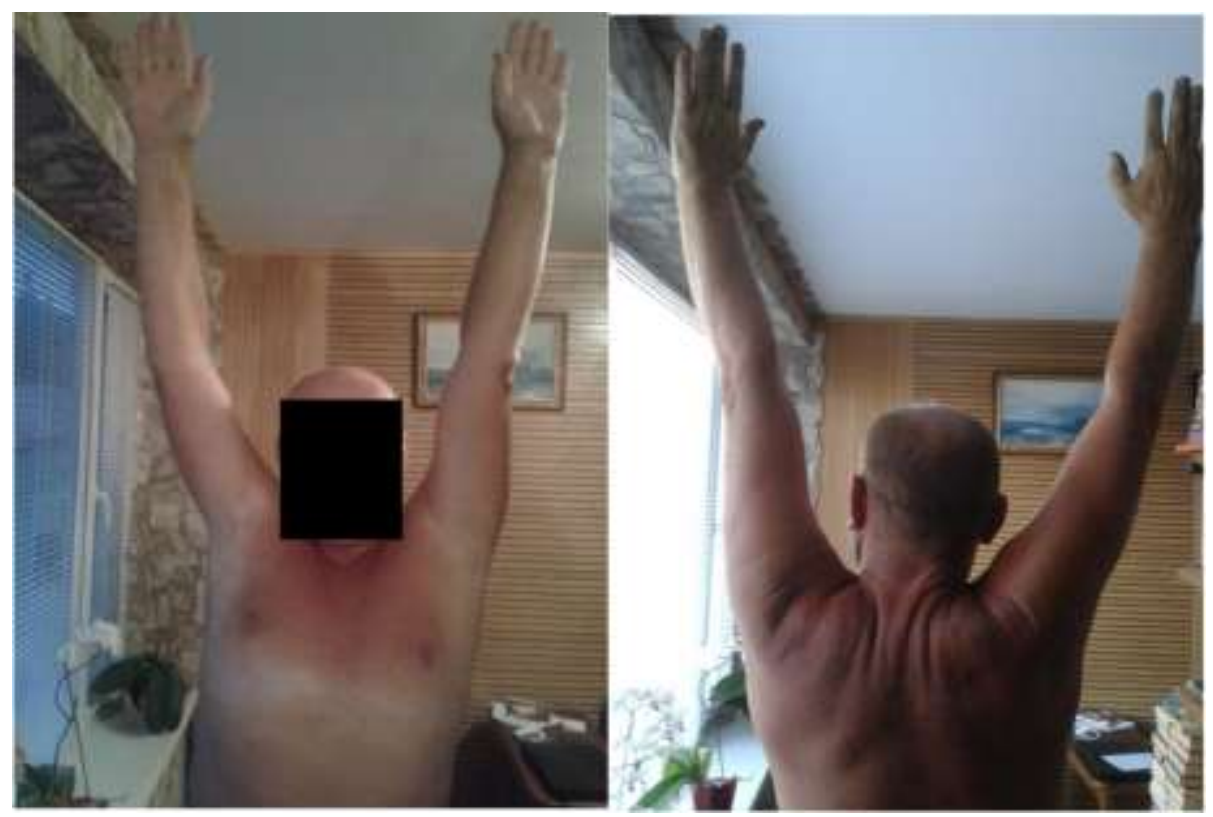

Figure 6. Patient 2: photo taken 24 months after the surgery

DISCUSSION. Synovial chondromatosis is a rare pathology characterized by multiple metaplasia sites in the synovium featuring loose intraarticular bodies [1; 4]. PSC etiology remains an open question $[3 ; 8]$.

SC diagnosis is fundamentally based on medical history data, instrumental diagnostics (Xray, MRI, CT), while histology helps differentiate primary and secondary chondromatosis [1; 3]. PSC occurs spontaneously. SSC is mainly associated with a previous joint disease or injury in the medical history.

As of today, arthroscopy is the most popular SC treatment method; the method is to remove intraarticular bodies and to perform local synovectomy [9-11]. The arthroscopic removal of loose intraarticular bodies to treat shoulder SC was first demonstrated by Richman and Rose in 1990 [9]. An overview of Russian and international publications revealed isolated cases of total shoulder replacement [5-7].

\section{CONCLUSIONS.}

The authors believe that arthroscopy of major joints is associated with the ever better equipment available to hospitals, which means more and more patients can start proper treatment as early as possible. In synovial chondromatosis of the shoulder, arthroscopic treatment is preferable over open surgery, as it injures less and has a shorter recovery period. Arthroscopic removal of loose intraarticular bodies from the shoulder is the method of choice that must be offered to shoulder SC patients. It is this method that was used in one of the cases presented herein.

The other patient had numerous intraarticular bodies coupled with deforming osteoarthrosis; open surgery had to be performed to place a total reverse implant: a DePuy Delta Xtend. Both patients are doing well in the long term. 
FINANCIAL SUPPORT AND SPONSORSHIP

Nil.

CONFLICTS OF INTEREST

The authors declare no conflict of interest

SUPPLEMENTARY DATA (DOI)

\section{REFERENCES}

1. Tikhilov R.M., Dokolin S.Y., Vorobjev S.L. et al. Primary synovial chondromatosis of the shoulder (case report). [Pervichnyi sinovialnyi khondromatoz plechevogo sustava (sluchai iz klinicheskoi praktiki)]. Traumatology and Orthopedics of Russia - Travmatologiia i ortopediia Rossii, 2012, no 1, pp. 104-108, doi 10.21823/2311-2905-2012-0-1-124-130.

2. Buess E., Friedrich B. Synovial chondromatosis of the glenohumeral joint: a rare condition. Archives of Orthopaedic and Trauma Surgery. 2001, vol. 121, pp. 109-111, doi $10.1007 / \mathrm{s} 004020000168$.

3. Murphey M.D., Vidal J.A., Fanburg-Smith J.C. et al. Imaging of synovial chondromatosis with radiologic-pathologic correlation. Radiographics, 2007, vol. 27, pp. 1465-1488, doi 10.1148/rg.275075116.

4. Rodionova O.V., Zavadovskaia V.D., Zhogina T.V. et al. Case of radiation diagnosis of synovial chondromatosis [Sluchai luchevoi diagnostiki sinovial'nogo khondromatoza]. Medical Visualization - Meditsinskaia vizualizatsiia, 2009, no. 4, pp. 38-42.

5. Ji J.H., Shafi M., Jeong D.S. Secondary synovial chondromatosis of the shoulder. Knee Surgery, Sports Traumatology, Arthroscopy, 2015, vol. 23, no 9, pp. 2624-2627, doi 10.1007/s00167-0143024-3.

6. Mikailov I.M., Grigoriev P.V., Ptashnikov D.A. et al. Results of the proximal humerus endoprosthetic reconstruction after tumour resection. [Rezul'taty endoprotezirovaniia plechevogo sustava u bol'nykh c novoobrazovaniiami proksimal'nogo otdela plechevoi kosti]. Traumatology and Orthopedics of Russia - Travmatologiia i ortopediia Rossii, 2014, no. 4, pp. 27-35, doi: 10.21823/2311-2905-2012-0-1-124-130.

7. Nenashev D.V., Varfolomeev A.P., Maykov S.V. Analysis of long-term results of shoulder arthroplasty [Analiz otdalennykh rezul"tatov endoprotezirovaniia plechevogo sustava]. Traumatology and Orthopedics of Russia - Travmatologiia i ortopediia Rossii, 2012, no. 2, pp. 71-78. doi: 10.21823/2311-2905-2012--2-71-78.

8. McKenzie G., Raby N., Ritchie D. A pictorial review of synovial osteochondromatosis. European Radiology, 2008, vol. 18, no 11, pp. 2662-2669, doi 10.1007/s00330-008-1024-8.

9. Richman J.D., Rose D.J. The role of arthroscopy in the management of synovial chondromatosis of the shoulder. A case report. Clinical Orthopaedics and Related Research, 1990, vol. 257, pp. 91-93, doi 10.1097/00003086-199008000-00018.

10. Ranalletta M., Bongiovanni S., Calvo J.M. et al. Arthroscopic treatment of synovial chondromatosis 
of the shoulder: report of three patients. Journal of Shoulder and Elbow Surgery, 2009, vol. 18, no 3, pp. 4-8, doi 10.1016/j.jse.2008.12.003.

11. Urbach D., McGuigan F.X., John M. et al. Long-term results after arthroscopic treatment of synovial chondromatosis of the shoulder. Arthroscopy, 2008, vol. 24, no 3, pp. 318-323, doi 10.1016/j.arthro.2007.08.034. 